\title{
Fetal outcome in Premature Rupture of Membrane - A study conducted in a tertiary level hospital in Bangladesh
}

\author{
*S Adhikary ${ }^{1}$, S Tanira ${ }^{2}$, A Sultana ${ }^{1}$, F Wazed ${ }^{4}$, SB Chowdhury ${ }^{5}$
}

\begin{abstract}
Background: Perinatal mortality is high if premature rupture of membrane (PROM) occurs when fetuses are of previable gestational age. Objective: To find out the effect of premature rupture of membrane in pregnancy on its fetal outcome. Methods: A cross-sectional study was conducted in Department of Obstetrics and Gynaecology of Bangabandhu Sheikh Mujib Medical University (BSMMU), Dhaka, Bangladesh, from February to July of 2008, on 50 pregnant women with more than 28 weeks of pregnancy both primigravid and multigravid with rupture of membranes prior to labour. Women who were admitted with rupture of membranes with established labour, or having antepartum hemorrhage, pre-eclampsia or eclampsia were excluded from the study. Out of 775 , only 95 patients were admitted with history of premature rupture of membrane (PROM). Among those patients, 50 cases were included in this study as per inclusion and exclusion criteria. Then their mode of delivery and outcome of fetal parameters were recorded. Results: 48 live births were observed and there were 2 fetal losses. Among 48 live newborns, 28 (58.33\%) were male and 20 $(41.66 \%)$ were female. $54.16 \%$ of babies had APGAR score at 5 minutes after birth was $>7$ and those needed no treatment. APGAR score was $\square 7$ in $45.82 \%$ babies; all of them were treated and cured. Among the newborns, $52.08 \%$ babies had birth weight $>2500 \mathrm{gm}, 45.83 \%$ had their birth weight in between 1500 and $2500 \mathrm{gm}$, while 1 (2.08\%) was between 1000 and $1500 \mathrm{gm}$. However, $22(45.83 \%)$ were affected by the consequences of PROM and birth process. Among them, 36.36\% developed jaundice, $29.27 \%$ suffered from birth asphyxia, and RTI and neonatal sepsis were evident in $18.18 \%$ each. $15 \%$ babies were treated conservatively in Department of Obstetrics, while $7 \%$ babies were treated in the Neonatal Ward under Department of Paediatrics after admission. There was no neonatal loss. Conclusion: Despite progress in obstetric and neonatal care over the past few years, fetal outcomes in pregnancies with PROM remains disappointing to date.
\end{abstract}

Keywords: Premature rupture of membrane, Fetal outcome, APGAR score.

1. Dr. Sanchita Adhikary, Junior Consultant, Department of Gynaecology \& Obstetrics, Jessore Sadar Hospital, Jessore. Email: drsadhikary@gmail.com

2. Dr. Shaorin Tanira, Assistant Director (Health), MCH-FP Clinic, Manabik Shahajya Sangstha (MSS), Dhaka.

3. Dr. Arifa Sultana, Senior Registrar, Department of Gynaecology \& Obstetrics, Apollo Hospitals, Dhaka.

4. Professor Dr. Feroza Wazed, Department of Gynaecology \& Obstetrics, Dhaka Medical College \& Hospital, Dhaka.

5. Professor Dr. Saleha Begum Chowdhury, Department of Gynaecology \& Obstetrics (Ex.), Bangabandhu Sheikh Mujib Medical University (BSMMU), Dhaka. 
Introduction

Premature rupture of membrane (PROM) is defined as spontaneous rupture of membrane before the initiation of labour. It is one of the common complications of pregnancy that has a major impact on maternal outcome. PROM affects $2.7 \%-17 \%$ of all pregnancies and however, in most cases, it happens spontaneously. ${ }^{1}$ Under normal circumstances, the fetal membranes rupture during the active phase of labour; however, PROM occurs before the onset of uterine contraction. When rupture of membrane occurs beyond 37 weeks of pregnancy, it is called term premature rupture of membrane (TPROM) and when it occurs before $37 \mathrm{com}$ pleted weeks it is called preterm premature rupture of membrane (PPROM). The rupture of membranes for $>24$ hours before delivery is called prolonged rupture of membrane 1. PROM is responsible for about $30 \%$ of all preterm delivery and its consequences. ${ }^{2}$ Preterm PROM is associated with significant maternal risks. preterm PROM occurs in 3\% of all pregnancy and contributes to approximately one-fourth to one-third of preterm births. ${ }^{3}$ Accurate assessment of the integrity of the membrane is very essential, because increased risk of infection, placental abruption, cord prolapse are observed with PROM. ${ }^{4-7}$ The aim of the present study is to find out the effect of PROM on fetal outcome and enrich the knowledge pool for the obstetricians to ensure correct management of PROM, which can ultimately reduce the mortality and morbidity caused by it.

\section{Materials and methods}

This was a cross-sectional study. Fifty pregnant women both primigravid and multigravid with rupture of membranes were included in this study. These patients were admitted and treated in the Department of Obstetrics and Gynaecology in Bangabandhu Sheikh Mujib Medical University (BSMMU) Hospital, Dhaka, Bangladesh, from February to July of 2008.

\section{Inclusion criteria:}

1. Both primigravid and multigravid women with PROM.

2. Duration of pregnancy is more than 28 weeks.

3. History of spontaneous rupture of membrane before initiation of labour.

\section{Exclusion criteria:}

1. History of rupture of membrane with established labour.

2. Women who are suffering from antepartum haemorrhage, pre-eclampsia, or eclampsia.

After admission, history of presenting complaints including duration of pregnancy, duration of rupture of membrane, lower abdominal pain, past history of rupture of membrane, past obstetric history - all were recorded. Gestational age was determined from first date of the last menstrual period (LMP), early ultrasonographic study, clinical examination and previous antenatal records. Moreover, socio-economic condition and special records e.g. coital habit, previous MR, D\&C also were documented. After taking the history a general and per abdominal examination was done for every patient. Then a sterile per speculum examination was done to assess cervical condition and stage of labour. Relevant investigations were also done to confirm diagnosis, select management strategy and exclude the other possibilities.

Diagnosis of rupture of membrane was done by:

i. History of a gush of fluid from the vagina

ii. Continuous leakage of fluid from the vagina

iii. Demonstration of amniotic fluid leakage from the cervix by a sterile speculum examination or pooling of amniotic fluid in posterior vaginal fornix.

iv. Demonstration $\mathrm{PH}$ of the vaginal fluid by litmus paper.

v. Demonstration of oligohydramnios by ultrasonography as a supporting method 
(when available).

Then plan of management of the patient with PROM was decided on the condition of the patient duration of pregnancy, duration of membrane rupture and intervention already made. A standard management protocol was followed, as suggested by Medina and Hill7. Uncomplicated babies were managed in the Department of Obstetrics and Gynaecology, while complicated babies were referred to the Neonatal Ward under Department of Paediatrics.

\section{Data Collection and Presentation:}

An informed consent was taken from each of the participants of the study. A semistructured questionnaire was prepared and the data were collected by directly questioning the patients and by physical examination, daily follow up of patients till their discharge from the hospital. However, fetal outcome was also observed and recorded. Data were presented in tables.

\section{Results}

Among fifty participants, two patients having gestational age $<34$ weeks ended with fetal loss. Among 48 live newborns, 28 (58.33\%) were male, while $20(41.66 \%)$ were female. The present study showed that $54.16 \%$ of babies had APGAR score at 5 minutes after birth was $>7$ and those needed no treatment. APGAR score was $\square 7$ in $45.82 \%$ babies; all of them were treated and cured (Table 01).
$52.08 \%$ babies had birth weight $>2500 \mathrm{gm}$, $45.83 \%$ had their birth weight in between 1500 and $2500 \mathrm{gm}$, while 1 (2.08\%) was between 1000 and $1500 \mathrm{gm}$ (Table 02). In this study, out of 48 alive babies $22(45.83 \%)$ were affected by the consequences of PROM and birth process. Among them, 36.36\% developed jaundice, $29.27 \%$ developed birth asphyxia, $18.18 \%$ each developed acute respiratory infection (ARI) and neonatal sepsis. $15 \%$ babies were treated conservatively in Department of Obsterics \& Gynaecology, while $7 \%$ babies were sent to the Neonatal Ward under Department of Paediatrics, got admitted and treated there. However, there was no neonatal loss (Table 03).

Table 01: APGAR score at 5 minutes ( $n=48)$

\begin{tabular}{|c|c|c|}
\hline $\begin{array}{c}\text { APGAR } \\
\text { score }\end{array}$ & $\begin{array}{c}\text { Number of } \\
\text { babies }\end{array}$ & $\begin{array}{c}\text { Percentage } \\
\mathbf{( \% )}\end{array}$ \\
\hline$>7$ & 26 & 54.16 \\
\hline $5-7$ & 20 & 41.66 \\
\hline$<5$ & 2 & 4.16 \\
\hline
\end{tabular}

Table 02: Weight at birth $(n=48)$

\begin{tabular}{|c|c|c|}
\hline Weight (gm) & $\begin{array}{c}\text { Number of } \\
\text { babies }\end{array}$ & $\begin{array}{c}\text { Percentage } \\
\text { (\%) }\end{array}$ \\
\hline$>2500$ & 25 & 52.08 \\
\hline $1500-2500$ & 22 & 45.83 \\
\hline $1000-1500$ & 01 & 2.08 \\
\hline
\end{tabular}

Table 03: Distribution of fetal outcome $(n=48)$

\begin{tabular}{lccc}
\hline \multicolumn{1}{c}{ Disease } & No. of babies (\%) & $\begin{array}{c}\text { Conservative treatment } \\
\text { in Obs. Dept. } \\
\text { No. of babies (\%) }\end{array}$ & $\begin{array}{c}\text { Admitted and treated } \\
\text { in Neonatal Ward } \\
\text { No of babies (\%) }\end{array}$ \\
\hline No morbidity & $\mathbf{2 6 ( 5 5 . 7 3 \% )}$ & & \\
\hline Morbidity & $\mathbf{2 2 ( 4 5 . 2 7 \% )}$ & & $2(9.09 \%)$ \\
Asphyxia & $6(29.27 \%)$ & $4(18.18 \%)$ & $3(13.63 \%)$ \\
ARI & $4(18.18 \%)$ & $1(4.54 \%)$ & $2(9.09 \%)$ \\
Jaundice & $8(36.36 \%)$ & $6(29.27 \%)$ & $0(0.0 \%)$ \\
Neonatal sepsis & $4(18.18 \%)$ & $4(18.18 \%)$ & \\
\hline
\end{tabular}


Discussion

Preterm premature rupture of membranes (PROM) at any stage of gestation complicates approximately $1 \%$ of pregnancies in the United States and is associated with significant risk of neonatal morbidity and mortality. ${ }^{7-9}$ Perinatal mortality is high if PROM occurs when fetuses are of previable gestational age. ${ }^{7}$ Moretti and Sibai10 reported an overall survival rate of $50 \%$ to $70 \%$ after delivery at 24 to 26 weeks of gestation. Bangabandhu Sheikh Mujib Medical University (BSMMU) is a tertiary level teaching and specialized hospital and always burdened with referred and complicated cases. ${ }^{11}$ Fetal morbidity and mortality following PROM is quite high in our country. ${ }^{12}$ In the current study, the incidence of neonatal complications is also high. The number of neonatal complications documented in our study appears to be as same as those provided in previous studies in our country. ${ }^{11-14}$ This result may be the effect of delivery occurred at an earlier gestational age. However, it may also possibly indicate that the complications witnessed are related more closely to the effects of premature birth rather than PROM. ${ }^{15}$ Despite progress in obstetric and neonatal care over the past years, fetal outcome in pregnancies with PROM still remains pitifully disappointing. In contrast, the present study reported no neonatal loss which is exceptionally better than that of Akter et al. ${ }^{11}$, Sultana et al. ${ }^{12}$, Tasnim and Bhuiyan ${ }^{13}$, Chowdhury et al. ${ }^{14}$ This may attribute advance management and neonatal ICU support of Bangabandhu Sheikh Mujib Medical University (BSMMU) hospital. Physicians caring for pregnant patients should be versed in the management of PROM, because rapid diagnosis and appropriate management can result in improved outcomes. $^{7}$

\section{Conclusion}

Despite progress in obstetric and neonatal care over the past few years, fetal outcome in pregnancies with $\mathrm{PROM}$ remains a frustration to date. However, if expectant management is desired, obstetricians should counsel their pregnant patients thoroughly and well in advance with regards to the poor outcomes for neonates anticipated after this type of delivery. Moreover, we recommend further studies with larger study participants and both in rural and urban areas to see the real scenario and trends in such obstetric management.

\section{Acknowledgement}

We would like to express our gratitude to the authority of Bangabandhu Sheikh Mujib Medical University (BSMMU), Dhaka, for permission to carry out the study and to the participants for their enormous cooperation.

\section{References}

1. Arias F, Daftary SN, Bhide AG. Premature Rupture of Membranes. In: Practical Guide to High-Risk Pregnancy and Delivery: A South Asian Perspective. 3rd ed. New Delhi: Elsevier; 2008: 240-61.

2. Konar H. Preterm Labor, Preterm Rupture of the Membranes, Postmaturity, Intrauterine Death of the Fetus. In: DC Dutta's Textbook of Obstetrics, 7th ed. New Delhi: Jaypee Borthers; 2013: 317-8.

3. Mercer BM. Preterm premature rupture of the membranes. Obstet Gynecol. 2003;101(1):178-93.

4. Shim SS, Romero R, Hong JS, et al. Clinical significance of intra-amniotic inflammation in patients with preterm premature rupture of membranes. Am J Obstet Gynecol. 2004;191(4):1339-45.

5. Mercer BM, Miodovnik M, Thurnau GR, et al. Antibiotic therapy for reduction of infant morbidity after preterm premature rupture 
of the membranes: a randomized controlled trial. National Institute of Child Health and Human Development Maternal-Fetal Medicine Units Network. JAMA. 1997;278(12):989-95.

6. Kenyon SL, Taylor DJ, Tarnow-Mordi W; ORACLE Collaborative Group. Broadspectrum antibiotics for preterm, prelabour rupture of fetal membranes: the ORACLE-I randomised trial. ORACLE Collaborative Group. Lancet. 2001;357(9261):979-88.

7. Medina TM, Hill DA. Preterm premature rupture of membranes: diagnosis and management. Am Fam Physician. 2006;73(4):659-64.

8. Nourse CB, Steer PA. Perinatal outcome following conservative management of mid-trimester pre-labour rupture of the membranes. J Paediatr Child Health. 1997;33(2):125-30.

9. Fortunato SJ, Welt SI, Eggleston MK Jr, Bryant EC. Active expectant management in very early gestations complicated by premature rupture of the fetal membranes. J Reprod Med. 1994;39(1):13-6.

10. Moretti M, Sibai BM. Maternal and perinatal outcome of expectant management of premature rupture of membranes in the midtrimester. Am J Obstet Gynecol. 1988;159(2):390-6.

11. Akter S, Akter R, Rashid M. Preterm prelabour rupture of the membrane \& feto-maternal outcome: an observational study. J Bangladesh Coll Phys Surg. 2010;28(1):17-23.

12. Sultana J, Chowdhury TA, Khan MH, Begum K. Amniotic fluid index values after preterm premature rupture of the membranes and subsequent prenatal infections. Bangladesh J Obstet Gynaecol. 2005;20(2):51-5.

13. Tasnim S, Bhuiyan AB. Outcome of premature rupture of membranes. Bangladesh J Obstet Gynaecol. 1998;13(1):16-20.

14. Chowdhury SR, et al. Incidence and outcome of preterm premature rupture of membranes and preterm labour at Holy Family Red Crescent Medical College Hospital. Bangladesh J Obstet Gynaecol. 2005;20(1):19-24.

15. Puri M, Patra S. Preterm Premature Rupture of Membranes. In: Krishna U, Shah D, Salvi V, Sheriar N, Damania KR. eds. Pregnancy at Risk: A Practical Approach to High Risk Pregnancy and Delivery. 5th ed. New Delhi: Jaypee Brothers; 2010: 512-8. 